\title{
1 Anomalous isotopes trace sulfur and gold pathways in magmatic arcs
}

2 V. Selvaraja ${ }^{1,2}$, M.L. Fiorentini ${ }^{1,2}$, C.K. LaFlamme ${ }^{1,2}$, B.A. Wing ${ }^{3}$, T.H. Bui ${ }^{3}$,

$3 \quad{ }^{I}$ Centre for Exploration Targeting, School of Earth Sciences, University of Western Australia

$4 \quad{ }^{2}$ ARC Centre of Excellence in Core to Crust Fluid Systems, University of Western Australia

$5 \quad{ }^{3}$ Department of Earth and Planetary Sciences and GEOTOP, McGill University

6 Abstract

7 Sulfur plays a crucial role in numerous Earth processes: it is central to metabolic synthesis and

8 biological evolution ${ }^{1}$, its variable concentration in the oceans and atmosphere significantly affects

9 the global climate ${ }^{2}$, and it is the most important carrier for precious metals accumulated in ore

10 deposits $^{3}$. Sulfur is transferred among different geochemical reservoirs in arcs, which are the

11 geological expression of subduction processes at convergent plate boundaries. However, a clear

12 understanding of the transport mechanism of sulfur has been obscured by a lack of distinct markers

13 to uniquely fingerprint this element and trace its pathway in $\operatorname{arcs}{ }^{4,5}$. These knowledge gaps are

14 addressed in this study by examining the indelible nature of the mass-independent fractionation of

15 sulfur (MIF-S) prior to 2.5 billion years ago, in the Archaean eon. This fractionation process led to

16 the formation of rocks with anomalous sulfur isotope signatures ${ }^{6-8}$. Just as radio-isotope dyes are

17 used in the medical sciences to map the intricate pathways of the inner human body, we have traced

18 the MIF-S anomalous signature to illuminate the pathway of sulfur through the Earth's upper

19 mantle and crust in the ca. 2 billion year old Glenburgh arc in Western Australia. Results from

20 high-precision sulfur isotope analysis indicate that the breakdown of MIF-S-bearing pyrite in

21 sediments from the Yilgarn Craton that subducted beneath the Glenburgh arc released sulfur that

22 mixed with sulfur derived from seawater sulfate minerals. The resulting MIF-S-bearing fluid

23 migrated through the mantle and crust, transporting the gold that is found in the Glenburgh gold

24 deposit. These findings revolutionise the current knowledge of the sulfur cycle on Earth and may

25 lead to a step change in the understanding of the planetary flux of volatiles and metals. 
The Earth's crust represents a complex and dynamically evolving chemical interface between two convective fluid systems: the endosphere (linked core and mantle) and the exosphere (linked hydrosphere and atmosphere). The nature of the physical and chemical processes that occur on the surface of the planet are intimately linked by the energy available from sharp chemical and thermal gradients that exist across this interface. The flux of volatiles and metals from the endosphere through to the exosphere is best recorded in arcs, which are the natural factories where juvenile continental crust is formed, where explosive volcanic eruptions emit large quantities of sulfurbearing gases into the atmosphere ${ }^{9}$, and where significant concentrations of precious metals are accumulated in sulfide-rich rocks ${ }^{5}$.

This study focuses on the ca. 2 billion year old (Ga) Glenburgh sulfide-bearing gold deposit in Western Australia, which formed when the Glenburgh Terrane collided with the Yilgarn Craton resulting in a period of subduction and magmatism and in the progressive closure of an ocean ${ }^{10,11}$. This geodynamic scenario occurred in the Paleoproterozoic (2.5-1.6 billion years ago), when our planet underwent profound and irreversible changes. These changes included the development of a complex life-supporting oxygenated atmosphere ${ }^{12}$ and the generation of new continental crust ${ }^{13}$ in environments akin to modern $\operatorname{arcs}^{12}$, where Archaean blocks collided and amalgamated into the supercontinent Columbia ${ }^{14}$. In these settings, significant amounts of volatiles and metals were circulated and focused to form some of the largest ore deposits on Earth ${ }^{5}$.

Our natural laboratory, the Glenburgh sulfide-bearing gold deposit, is hosted within $<2.04 \mathrm{Ga}$ metasedimentary rafts in the ca. 2.0 Ga Dalgaringa Supersuite, which intrudes the Glenburgh Terrane $^{10}$. The deposit formed between $2.04 \mathrm{Ga}$ and $1.99 \mathrm{Ga}^{11}$, synchronous with subduction and $\operatorname{arc}$ magmatism ${ }^{10}$. In order to constrain the link between the sulfur cycle, precious metal transport, and the geodynamic evolution of the Glenburgh arc, thirty-six samples were obtained from the

50 Glenburgh gold deposit and from nearby intercalated magmatic rocks of the Dalgaringa Supersuite 51 to investigate their multiple sulfur isotopic signatures. Analyses were performed at the Stable 
Isotope Laboratory at McGill University, Canada. Sulfide-bearing samples were microdrilled to generate a pure sulfide powder, whereas sulfide-free but sulfur-bearing whole rocks were milled into a fine powder so as to facilitate extraction of the sulfur disseminated in the mineralogy of the rocks. Both powder suites were dissolved and analysed by gas fluorination mass spectrometry ${ }^{15}$.

We investigated two multiple sulfur isotope signatures: 1) the mass-dependent fractionation of sulfur (defined as $\delta^{34} \mathrm{~S}$ ), which is sensitive to physical processes that occur during the hydrothermal circulation of fluids ${ }^{16}$; and 2 ) the mass-independent fractionation of sulfur (MIF-S; defined as $\Delta^{33} \mathrm{~S}$ and $\left.\Delta^{36} \mathrm{~S}\right)^{6}$, which is a chemically conservative signature that fingerprints the source of sulfur through a wide range of geological processes ${ }^{17}$. Non-zero $\Delta^{33} \mathrm{~S}$ and $\Delta^{36} \mathrm{~S}$ values, reflected in the fractionation of ${ }^{33} \mathrm{~S}$ and ${ }^{36} \mathrm{~S}$ away from the mass-dependent fractionation relationship, were generated by the bombardment of S-bearing gases by short wavelength UV rays in the oxygen-poor Archaean atmosphere, prior to the Great Oxygenation Event (GOE) at $2.45 \mathrm{Ga}^{6,7,18}$. The photochemical products of these reactions led to positive $\Delta^{33} \mathrm{~S}$ values in sedimentary pyrite and negative $\Delta^{33} \mathrm{~S}$ in reservoirs derived from oceanic sulfate ${ }^{8}$. Once formed in the Archaean, these nonzero MIF-S signatures cannot be erased, only diluted in the terrestrial and marine geological record.

The analysed samples yielded $\Delta^{33} \mathrm{~S}$ values ranging from $0.22 \%$ to $0.82 \%$ (uncertainties on $\Delta^{33} \mathrm{~S}$ below $\pm 0.01 \%$ ),$\Delta^{36} \mathrm{~S}$ values from $-0.91 \%$ to $0.27 \%$ (uncertainties on $\Delta^{36} \mathrm{~S}$ below $\pm 0.1 \%$ ) and $\delta^{34} \mathrm{~S}$ values between $1.8 \%$ and $11.6 \%$ (uncertainties on $\delta^{34} \mathrm{~S}$ below $\pm 0.15 \%$; Fig. 1 ). The Halfway Gneiss, the ca. 2.5 Ga basement rock that hosts the Dalgaringa Supersuite and the Glenburgh gold deposit, yielded sulfur contents below the extraction threshold ( $<50$ parts per million). The linear slope of the relationship between $\Delta^{36} \mathrm{~S}$ and $\Delta^{33} \mathrm{~S}$ in the sulfide-bearing samples and associated magmatic rocks of the ca. 2.0 Ga Dalgaringa Supersuite is -1.361 , which fits well within the Archaean reference array of MIF-S measurements ${ }^{7}$. These results are unexpected as the Glenburgh 5 sulfide-bearing gold mineralisation and nearby magmatic rocks display MIF-S signatures that are among the largest documented anomalies in rocks formed after the $\mathrm{GOE}^{7}$. 
This opens up the question of how these anomalous MIF-S signatures were recorded and preserved in a gold deposit that formed in a Proterozoic arc. It has been suggested that anomalous $\Delta^{33} \mathrm{~S}$ fractionation may be generated by thermochemical sulfate reduction, where $\mathrm{SO}_{4}{ }^{2-}$ is reduced by amino acids to $\mathrm{H}_{2} \mathrm{~S}^{19}$. However, the experimental simulations of that process ${ }^{20}$ are not able to reproduce the large deviations in both $\Delta^{33} \mathrm{~S}$ and $\Delta^{36} \mathrm{~S}$ that are observed in this study. A more likely mechanism to generate the positive $\Delta^{33} \mathrm{~S}$ anomaly is through the involvement of $\mathrm{S}_{8}$ colloids exposed to a pre-2.45 Ga atmosphere, where they underwent high wavelength UV photochemical reactions ${ }^{6 \text {, }}$ ${ }^{8}$. In the Archaean eon, these $\mathrm{S}_{8}$ colloids were deposited as sediment-hosted pyrite at the bottom of the water column in iron- and carbon-rich shales ${ }^{8}$. Thus, the $\Delta^{33} \mathrm{~S}$ values recorded in the ca. $2.0 \mathrm{Ga}$ Glenburgh gold deposit and surrounding Dalgaringa Supersuite are indicative of the input of Archaean shale-derived sedimentary pyrite . $^{8}$

The conundrum lies in the fact that the rocks that host the Glenburgh gold deposit are largely Proterozoic in age, and hence are not likely the original sources of MIF-S. The only Archaean unit in the observed stratigraphy is the ca. 2.5 Ga Halfway Gneiss, which comprises the regional country rocks that host the Dalgaringa Supersuite and the Glenburgh gold deposit. However, it is improbable that the Halfway Gneiss contributed to the sulfur isotope signature recorded in the Glenburgh gold deposit for two reasons: 1) it has a very low sulfur content ( $<50$ parts per million), and 2) it is an orthogneiss with a granitic protolith ${ }^{21,22}$ and as such it is unlikely to contain any Archaean surface-derived sulfur. We present here a compelling model to explain the observed large MIF-S signatures in the Proterozoic Glenburgh gold deposit.

This model is based upon the observation that multiple sulfur isotope data spread along a mixing line between two end-member sulfur reservoirs in $\delta^{34} \mathrm{~S}-\Delta^{33} \mathrm{~S}$ space (Fig. 1). The first end-member reservoir is Archaean shale-derived sedimentary pyrite $\left(\delta^{34} \mathrm{~S}=\leq 0 \% ; \Delta^{33} \mathrm{~S}=\geq 1 \%\right.$, whereas the second end-member is sulfur derived from seawater sulfate at ca. $2.0 \mathrm{Ga}\left(\delta^{34} \mathrm{~S}=20 \%\right.$; $\Delta^{33} \mathrm{~S}=$ $0 \%)^{23}$. We argue that the first end-member reservoir is likely to be derived from the metamorphic devolatilisation of Archaean pyritic carbonaceous sedimentary rocks of the Yilgarn Craton during 
103

subduction below the Glenburgh Terrane, generating arc magmatism and mineralising fluids (Fig. 2). The second end-member reservoir of seawater-sourced sulfur can be explained by devolatilisation of Paleoproterozoic seawater-derived sulfate minerals contained in the subducted sediments ${ }^{4}$.

Mixing between the two distinct sulfur isotope reservoirs occurred during subduction of dense mafic crust located at the margin of the Archaean Yilgarn Craton ${ }^{24}$. Dehydration metamorphic reactions drove the breakdown of Archaean pyrite, hosted in the shale sediments overlying the subducting mafic crust, contemporaneously with the breakdown of ca. 2.0 Ga seawater-derived sulfate minerals. The resulting sulfur-rich hydrothermal fluids ${ }^{25}$ metasomatised the mantle wedge, driving partial melting of the sub-continental mantle lithosphere. Subsequently, mantle-derived melts containing the mixed isotopic signature ascended diapirically through the crust, undergoing crustal assimilation and fractional crystallization to form the buoyant andesitic magmas ${ }^{5}$, which crystallised as the large batholiths of the Dalgaringa Supersuite.

By constraining the source of sulfur, it is possible to also identify the source and transfer mechanisms of gold that operated in the Glenburgh arc. It has been suggested that the ultimate source of gold in continental arc-hosted gold deposits is from subducted carbon-rich sedimentary rocks ${ }^{25}$. However, this hypothesis has never been conclusively tested. Given the insoluble nature of gold $(\mathrm{Au})$ in $\mathrm{H}_{2} \mathrm{O}$, it would have to be mobilised as an $\mathrm{Au}(\mathrm{HS})_{2}{ }^{-}$complex in fluids at high temperatures and pressures, such as those in arc magmatic environments ${ }^{26}$. Following this line of evidence, the ultimate source of gold should be the same as the source of sulfur, and the isotopic composition of sulfide in the deposit should reflect the isotopic signature of the subducted carbonrich sedimentary rocks, consistent with the dataset presented in this study. Thus, it is argued that sulfide complexes were responsible for the transfer of sulfur and gold from the subducted crust into the mantle wedge, and from there to the large batholiths of the Dalgaringa Supersuite, from which mineralising fluids exsolved to form the Glenburgh gold deposit. 
128 The data from this study provide new insights into the heavily debated topic of the mass balance 129 problem between the known concentrations of sulfur and gold in the mantle wedge below arcs and 130 the observed concentrations in arc magmas and associated mineralisation ${ }^{5,26,27,28}$. Isotope data 131 indicate that the contribution of sulfur from the mantle wedge is minimal. In fact, if a hypothetic 132 third isotopic reservoir for the depleted mantle displaying $\delta^{34} \mathrm{~S}=-1.3 \%$ and $\Delta^{33} \mathrm{~S}=0 \%{ }^{29}$ was 133 added, it would be apparent that the observed mixing line between the Archaean MIF-S-bearing 134 reservoir and the Proterozoic seawater sulfate is not deflected towards the depleted mantle end 135 member. By inference, it is possible to argue that the gold of the Glenburgh deposit is largely 136 derived from the Archaean carbon-rich sedimentary rocks subducted underneath the Proterozoic 137 Glenburgh arc, and not directly from the sulfides hosted in the mantle wedge ${ }^{29}$.

138 The application of chemically conservative isotopic tracers such as $\Delta^{33} \mathrm{~S}$ is critical for a better 139 understanding of magmatic and tectonic processes that drive fluid and metal transfer from Archaean 140 cratons into their reworked margins, where some of the largest ore deposits on Earth formed and are 141 currently preserved ${ }^{24}$. At the Glenburgh deposit, multiple sulfur isotope data show that mixing 142 between Archaean shale-derived pyrite sulfur with sulfur from Paleoproterozoic seawater-derived 143 sulfate records the onset of continent-continent collision between the Glenburgh Terrane and the 144 Yilgarn Craton. Hence, multiple sulfur isotope data are able to image a process that is cryptic to 145 most other currently available datasets, showing that sulfur and metal cycling in arc settings occurs 146 on very large scales, from the atmosphere-hydrosphere through to the lithosphere during crustal 147 generation. 


\section{References}

154 1. Canfield, D. E., Habicht, K. S. \& Thamdrup, B. The Archean Sulfur Cycle and the Early History of Atmospheric Oxygen. Science 288, (2000).

2. Canfield, D. E. \& Teske, A. Late Proterozoic rise in atmospheric oxygen concentration inferred from phylogenetic and sulphur-isotope studies. Nature 382, 127-132 (1996).

3. Seo, J. H., Guillong, M. \& Heinrich, C. A. The role of sulfur in the formation of magmatichydrothermal copper-gold deposits. Earth Planet. Sci. Lett. 282, 323-328 (2009).

4. Tomkins, A. G. \& Evans, K. A. Separate zones of sulfate and sulfide release from subducted mafic oceanic crust. Earth Planet. Sci. Lett. 428, 73-83 (2015).

5. Richards, J. P. Magmatic to hydrothermal metal fluxes in convergent and collided margins. Ore Geol. Rev. 40, 1-26 (2011).

6. Farquhar, J., Bao, H. \& Thiemens, M. Atmospheric Influence of Earth's Earliest Sulfur Cycle. Science 289, 756-758 (2000).

7. Johnston, D. T. Multiple sulfur isotopes and the evolution of Earth's surface sulfur cycle. Earth-Science Rev. 106, 161-183 (2011).

9. Wallace, P. J. Volatiles in subduction zone magmas: Concentrations and fluxes based on melt inclusion and volcanic gas data. J. Volcanol. Geotherm. Res. 140, 217-240 (2005).

172 10. Sheppard, S., Occhipinti, S. A. \& Tyler, I. M. A 2005-1970 Ma Andean-type batholith in the southern Gascoyne Complex, Western Australia. Precambrian Res. 128, 257-277 (2004).

11. Roche, L. K. Unravelling the upper amphibolite to granulite facies hosted Glenburgh Au deposit- metamorphosed gold? Glenburgh Terrane, Gascoyne Province, Western Australia. 
178 12. Kump, L. R. \& Barley, M. E. Increased subaerial volcanism and the rise of atmospheric oxygen 2.5 billion years ago. Nature 448, 1033-1036 (2007).

180 13. Cawood, P. A., Hawkesworth, C. J. \& Dhuime, B. The continental record and the generation of continental crust. Geol. Soc. Am. Bull. 125, 14-32 (2013).

182 14. Rogers, J. J. W. \& Santosh, M. Configuration of Columbia, a Mesoproterozoic 183 Supercontinent. Gondwana Res. 5, 5-22 (2002).

15. Canfield, D. E., Raiswell, R., Westrich, J. T., Reaves, C. M. \& Berner, R. A. The use of chromium reduction in the analysis of reduced inorganic sulfur in sediments and shales. Chem. Geol. 54, 149-155 (1986).

16. Ohmoto, H. Systematics of sulfur and carbon isotopes in hydrothermal ore deposits. Econ. Geol. 67, 551-578 (1972).

17. Bekker, A. et al. Atmospheric sulfur in Archaean komatiite-hosted nickel deposits. Science 326, 1086-1089 (2009).

191 18. Farquhar, J. \& Wing, B. A. Multiple sulfur isotopes and the evolution of the atmosphere. Earth Planet. Sci. Lett. 213, 1-13 (2003).

193 19. Ohmoto, H., Watanabe, Y., Ikemi, H., Poulson, S. R. \& Taylor, B. E. Sulfur isotope evidence for an oxic Archaean atmosphere. Nature 442, 908-911 (2006).

195 20. Oduro, H. et al. Evidence of magnetic isotope effects during thermochemical sulfate reduction. Proceedings of the National Academy of Sciences 108, 17635-17638 (2011).

197 21. Cawood, P. A. \& Tyler, I. M. Assembling and reactivating the Proterozoic Capricorn Orogen: Lithotectonic elements, orogenies, and significance. Precambrian Res. 128, 201200 22. Johnson, S. P. et al. Crustal architecture of the Capricorn Orogen, Western Australia and associated metallogeny. Aust. J. Earth Sci. 60, 681-705 (2013). 
23. Planavsky, N. J., Bekker, A., Hofmann, A., Owens, J. D. \& Lyons, T. W. Sulfur record of rising and falling marine oxygen and sulfate levels during the Lomagundi event. Proc. Natl. Acad. Sci. 1-6 (2012). doi:10.1073/pnas.1120387109

24. Mole, D. R. et al. Crustal evolution, intra-cratonic architecture and the metallogeny of an Archaean craton. Geol. Soc. London, Spec. Publ. 393, (2013).

25. Tomkins, A. G. Windows of metamorphic sulfur liberation in the crust: Implications for

26. Goldfarb, R. J. \& Groves, D. I. Orogenic gold: Common or evolving fluid and metal sources through time. Lithos (2015). doi:10.1016/j.lithos.2015.07.011

27. De Hoog, J. C. M., Taylor, B. E. \& Van Bergen, M. J. Sulfur isotope systematics of basaltic lavas from Indonesia: Implications for the sulfur cycle in subduction zones. Earth Planet.

28. Labidi, J., Cartigny, P. \& Moreira, M. Non-chondritic sulphur isotope composition of the

30. Ding, T. et al. Calibrated sulfur isotope abundance ratios three IAEA sulfur isotope reference materials and V-CDT with a reassessment of the atomic weight of sulfur. Geochim. Cosmochim. Acta 65, 2433-2437 (2001). terrestrial mantle. Nature 501, 208-11 (2013).

29. Saunders, J. E., Pearson, N. J., O’Reilly, S. Y. \& Griffin, W. L. Gold in the mantle: The role of pyroxenites. Lithos 244, 205-217 (2016).

\section{Acknowledgements}

223 The authors would like to acknowledge the support of the Geological Survey of Western Australia 224 and Gascoyne Resources Ltd for providing samples for this study. This work was financially 225 supported by the Minerals Research Institute of Western Australia (MRIWA), the Science and 226 Education Endowment Fund (SIEF) and the Australian Research Council (ARC), through the 
227 Centre of Excellence of Core to Crust Fluid Systems and the Future Fellowship awarded to MLF. 228 This work is part of the $\mathrm{PhD}$ thesis of VS, who acknowledges support from the University of 229 Western Australia through a SIRF scholarship. This is contribution no. XXX for the ARC Core to 230 Crust Fluid Systems Centre of Excellence. The Stable Isotope Laboratory in the Earth and Planetary 231 Science department at McGill is supported by the FQRNT through the GEOTOP research centre.

\section{Author Contributions}

233 V.S, C.K.L. and M.L.F. wrote the paper and V.S. prepared the figures and tables. V.S, M.L.F and 234 B.A.W. conceived the project. V.S. performed field work to obtain the samples and sample 235 preparation. V.S and T.H.B. performed the S-isotope analyses on all samples. All authors 236 participated in the discussion and interpretation of results, and preparation of the manuscript.

237 Author Information

238 The authors declare no competing financial interests. Readers are welcome to comment on the 239 online version of the paper. Correspondence and requests for materials should be addressed to 240 M.L.F (marco.fiorentini@uwa.edu.au) 


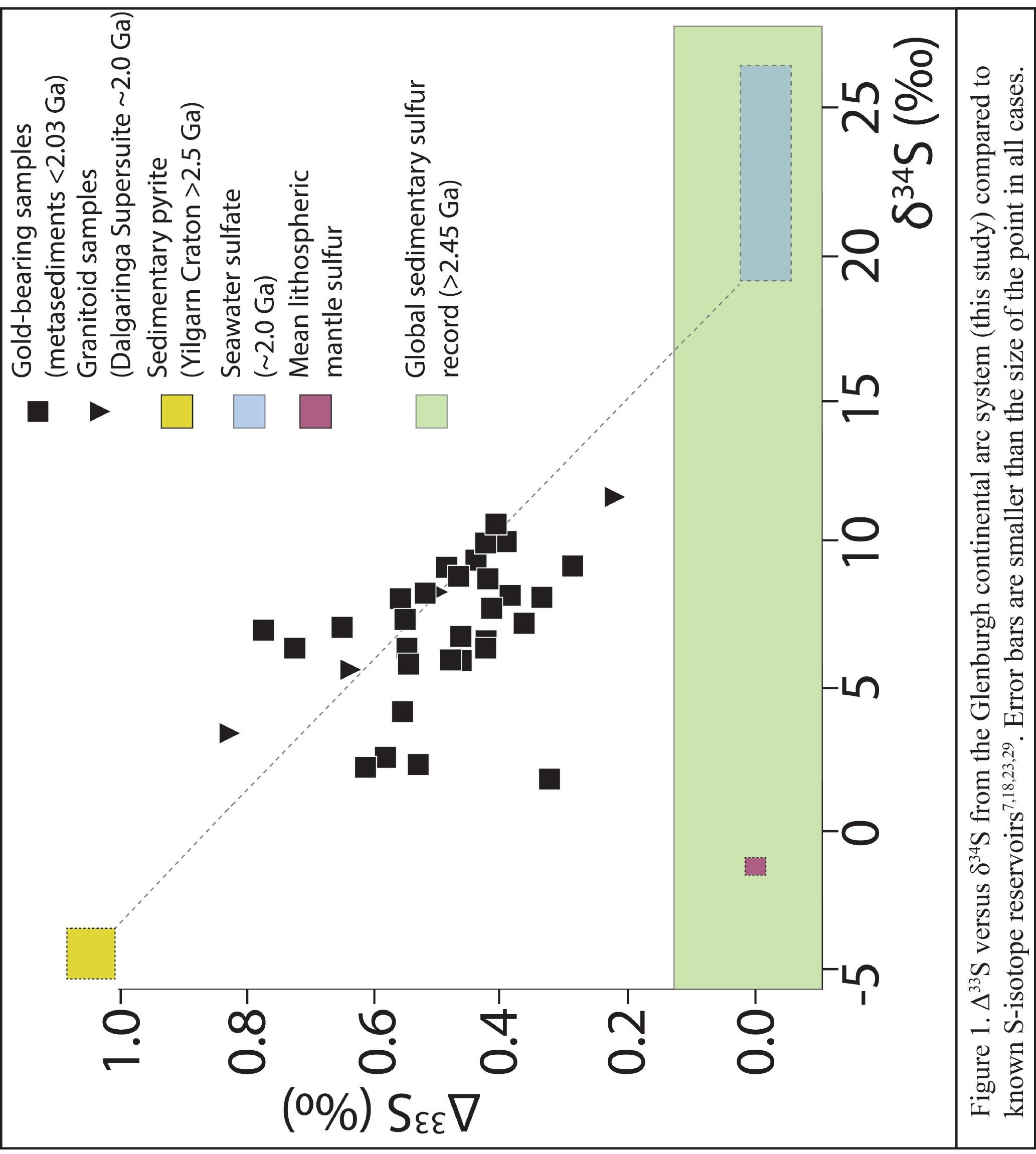




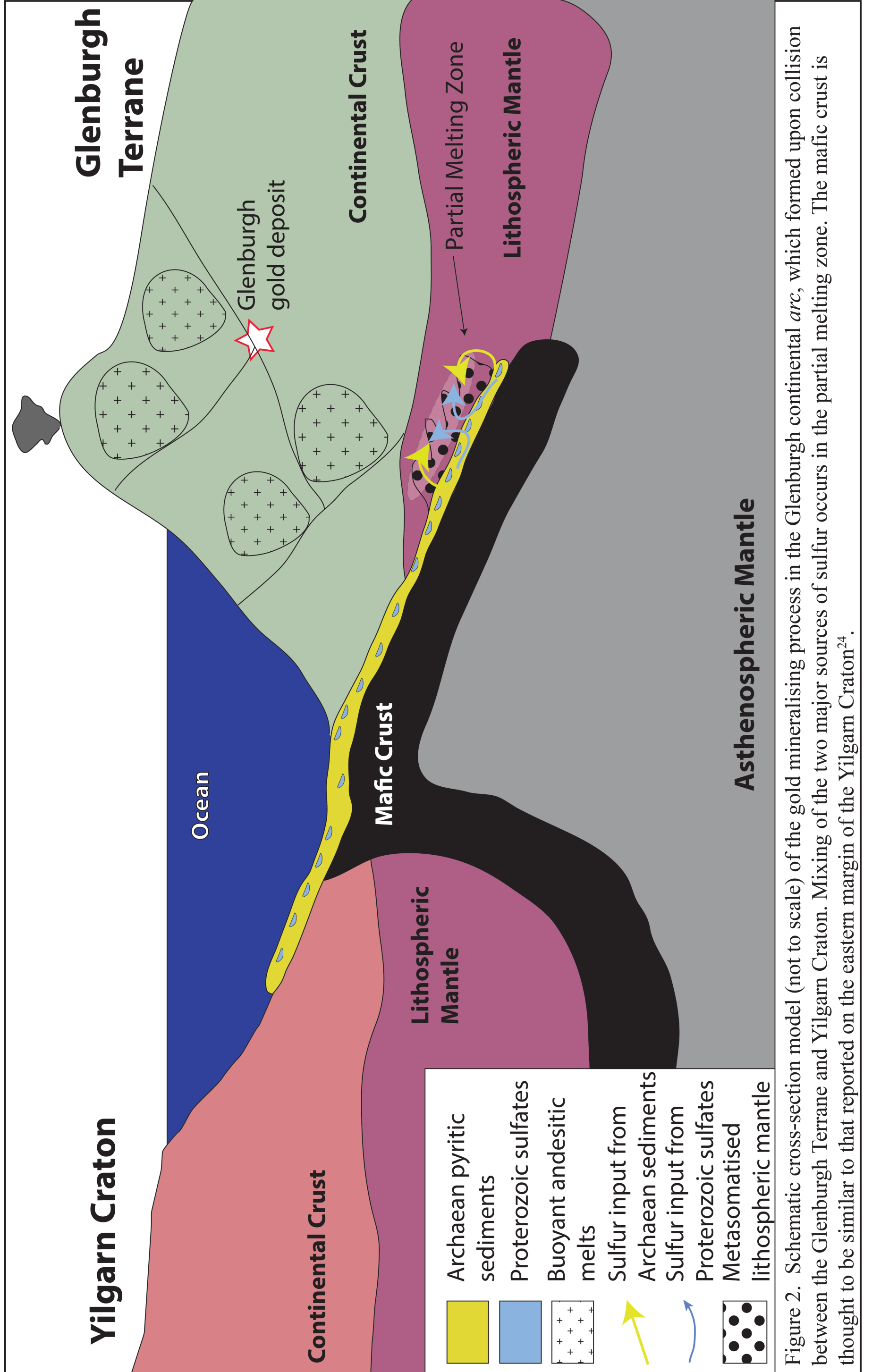

